\title{
Airway complications in lung transplantation
}

\author{
Maria M. Crespo \\ Pulmonary, Allergy and Critical Care Division, Hospital of the University of Pennsylvania, Philadelphia, PA, USA \\ Correspondence to: Maria M. Crespo, MD. Pulmonary, Allergy and Critical Care Division, Hospital of the University of Pennsylvania, Philadelphia, \\ PA, USA. Email: maria.crespo@pennmedicine.upenn.edu.
}

\begin{abstract}
Airway complications (ACs) after lung transplantation remain an important source of morbidity and mortality despite significant advances in the surgical technics, leading to increased cost, and decrease quality of life. The incidences of ACs after lung transplantation range from $2 \%$ to $33 \%$, even though most transplant centers have reported rates in the range of $7 \%$ to $8 \%$. However, the reported rate of ACs has been inconsistent as a result of a lack of standardized airway definitions and grading protocols before the recent 2018 International Society for Heart and Lung Transplantation (ISHLT) proposed consensus guidelines on ACs after lung transplantation. The ACs include stenosis, perioperative and postoperative bronchial infections, bronchial necrosis and dehiscence, excess granulation tissue, and tracheobronchomalacia (TBM). Anastomosis infection, necrosis, or dehiscence typically develops within the first month after lung transplantation. The most frequent AC after lung transplantation is bronchial stenosis. Several risk factors have been proposed to the development of ACs after lung transplantation, including surgical anastomosis techniques, hypoperfusion, infections, donor and recipient factors, immunosuppression agents, and organ preservation. ACs might be prevented by early recognition of the airway pathology, using advance medical management, and interventional bronchoscopy procedures. Balloon bronchoplasty, cryotherapy, laser photo resection, electrocautery, high-dose endobronchial brachytherapy, and bronchial stents placement are the most frequent interventional bronchoscopic procedures utilized for the management of ACs.
\end{abstract}

Keywords: Lung transplantation; airway complications (ACs); airway ischemia reperfusion and grading; anastomosis dehiscence; bronchial stenosis; endobronchial infections; bronchial balloon dilation; bronchial stent placement; risk factors

Submitted Mar 23, 2021. Accepted for publication Jul 13, 2021.

doi: $10.21037 /$ jtd-20-2696

View this article at: https://dx.doi.org/10.21037/jtd-20-2696

\section{Introduction}

In the early years after it was performed the first lung transplant in 1963 by Dr. James Hardy, bronchial complications, mainly necrosis, and dehiscence were the most frequent cause of morbidity and mortality in those patients who survived the first two post-operative weeks (1). Despite the high early incidence of airway complications (ACs), the recent advances made in organ preservation, surgical techniques, and the medical management of the recipient have contributed to a significant decreased in the ACs rates from as high as $80 \%$ to $15 \%(1-4)$. The reported incidence of ACs after lung transplantation has been inconsistent as a result of a lack of standardized definitions and grading protocols before the recent 2018 International Society for Heart and Lung Transplantation (ISHLT) proposed consensus guidelines on ACs after lung transplantation (5), which has been accepted as a universal airway grading by the lung transplant society. Contrary to the previous classification protocols, the ISHLT system grades the severity, location, and extent of each type of ACs including, ischemia, necrosis, dehiscence, stenosis, and malacia (Table 1). The ISHLT consensus also emphasized the importance of recognizing other airway pathologies, e.g., endobronchial fungal infections and endobronchial posttransplant lymphoproliferative disorder (PTLD), which can manifest as airway necrosis or stricture.

The management of ACs varies depending on the 
Table 1 ISHLT adult and pediatric grading system for airway complications after lung transplant

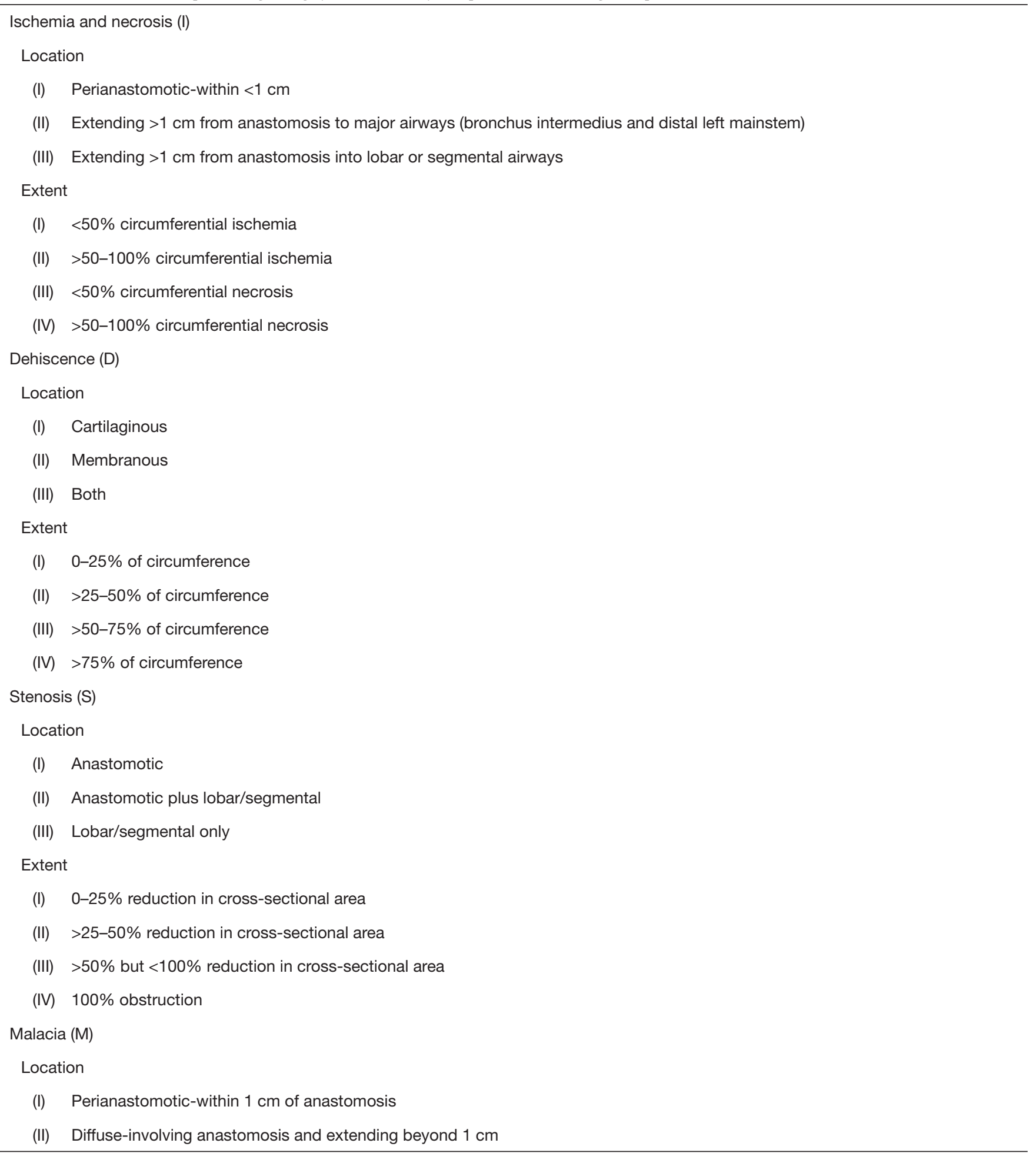

Reproduced from: Crespo MM, McCarthy DP, Hopkins PM, et al. ISHLT Consensus Statement on adult and pediatric airway complications after lung transplantation: definitions, grading system, and therapeutics. J Heart Lung Transplant 2018;37:548. Table used with the permission of Elsevier Inc. All rights reserved. ISHLT, International Society for Heart and Lung Transplantation. 
location and severity of the airway pathology, timing posttransplant, and institution's bronchoscopy surveillance protocols. Anastomotic ACs after lung transplant can involve the anastomosis or distal airways and include those that typically develop within the first month of surgery (e.g., anastomotic infection, necrosis, or dehiscence) and those that develop later (e.g., excess granulation tissue, bronchomalacia, airway stenosis, and fistula) (6-9). Patients with ACs often require frequent bronchoscopic interventions, causing a significant impact on their quality of life (3).

Impairment of blood flow in the immediate posttransplant is believed to be the principal cause of most ACs after lung transplantation (7-13). The bronchial and pulmonary circulations supply blood to the lungs. The bronchial circulation is the systemic vascular supply to the lung, large airways, and branches down to the level of the terminal bronchioles $(8,9)$. Seventy percent of the bronchial arteries usually arise directly from the thoracic aorta at the level of T5-T6 vertebra (10). There are usually three main bronchial arteries, one single right which originates from the intercostobronchial trunk, and two left that arise directly from the anterior surface of the thoracic aorta. During the lung harvest procedure, the bronchial blood supply is interrupted, leaving the bronchial vessels at the bronchial anastomotic site dependent on retrograde filling from the pulmonary artery circulation through communications in the submucosal plexus $(4,10)$. Attempts to restore the bronchial circulation surgically are rarely performed. The timing for revascularization of the donor bronchus by the recipient bronchial circulation is typically 2 to 4 weeks, placing the anastomotic site at risk for ischemia $(4,10)$.

\section{Risk factors}

Several factors have been related to an increased risk of anastomotic ACs. The major factors that increase the risk of ACs are those that increase anastomotic ischemia.

Surgical anastomosis techniques have an influence in the development of ACs. Several surgical techniques have been evolved over the years to improve the postoperative anastomotic ischemia, from a telescoped anastomosis, wrapping vascularized pedicles, end-to-end anastomosis, to bronchial artery revascularization (BAR), as described in the literature $(6-8,14-20)$. The technique of tracheal anastomosis has been abandoned due to the high incidence of anastomosis ischemia and ACs seen $(2,9,17)$. Reducing the length of the donor bronchus is key for minimizing anastomosis ischemia. The current surgical techniques involve minimizing the length to within one to two cartilaginous rings $(7,9,17)$. The biggest concern with telescoped bronchial anastomosis was a $48 \%$ rate of bronchial stenosis complications (14). The use of an endto-end anastomosis, with the anastomosis performed closer to the secondary carina, is associated with a low incidence of complications and is the preferred surgical technique at most institutions $(3,15)$. Few single-center publications have shown fewer rates of airway ischemia with the BAR technique $(18,20)$. The suture techniques may also play a role in the development of ACs $(17,21,22)$. Mulligan and colleagues described a lower rate of distal ACs from $12.2 \%$ to $4.4 \%$ in patients using a novel anastomotic technique, by performing the anastomosis at the secondary carina utilizing a combination of running and figure-of-eight sutures, minimizing donor bronchial ischemia (21). However, controversy remains regarding the optimal anastomotic technique.

Van De Wauwer and colleagues (17) found an increased risk of ACs post-transplant in patients receiving lungs from donors with prolonged ( $>50$ to $<70 \mathrm{~h}$ ) ventilation support, and in tall recipients. Few studies found no differences in the rate of airway ischemia using donation after circulatory determination of death (DCDD) donors, compared to donation after neurologic determination of death (DNDD) donors $(23,24)$.

It remains unclear the direct relationship between the extent of donor ischemic time and the incidence of ischemic ACs. The second anastomosis during a bilateral lung transplant is not at higher risk for ACs (25). Prolonged ischemic time observed with ex vivo lung perfusion is not associated with a higher risk of ACs (26). Nevertheless, prolonged ischemic times should be minimized due to its relation to lung transplant outcomes (27-29).

Patients who developed severe primary graft dysfunction (PGD) have a high rate of ACs (11,27-29). These patients have more extended mechanical ventilation and often require higher positive end-expiratory pressure (PEEP), which may decrease retrograde bronchial mucosa blood flow and increase the risk of airway ischemia $(3,11,12)$.

Organ preservation techniques and perioperative management may also have implications for airway ischemia and complications. Antegrade and retrograde administration of preservation solutions have shown better results than organs perfused only with antegrade administration $(30,31)$. Adding prostaglandin E1 was found to prolonged preservation times to up to $24 \mathrm{~h}$ safely (32). 
It remains unclear the role of airway infection in the development of ACs. However, preoperative and postoperative airway infections by both bacterial and fungal organisms have been related to high risk of ACs in some studies. Several organisms, especially fungi, including Aspergillus, Candida, Rhizopus, and Mucor species, have been associated with the development of ACs such as dehiscence, bronchial stenosis, and fistula formation $(22,33,34)$.

Several studies have demonstrated that using steroids pretransplant or early postoperative did not show any deleterious effects on the anastomotic site healing $(25,35)$. The use of mammalian target-of-rapamycin (mTOR) inhibitors, such as sirolimus, in the early post-transplant period, have been associated with an increased incidence of dehiscence $(36,37)$. It is recommended to avoid mTOR inhibitors until at least 90 days after transplant.

\section{Classification and management of ACs}

\section{Stenosis}

Bronchial stenosis typically occurs within the first two to nine months but has been reported to occur over a year after transplantation $(7,12,22)$. Patients with bronchial stenosis can present with dyspnea, cough, or wheezing, have declining flow rates on spirometry with abnormal flow-volume loop patterns, post obstructive pneumonia, or be asymptomatic and incidentally found on routine surveillance bronchoscopy. Central airway stenosis (CAS) is defined as stenosis at the bronchial anastomosis site or within $2 \mathrm{~cm}$ of the anastomosis. Distal airway stenosis (DAS) involves the airways distal to the anastomosis or the lobar bronchi. The incidence of DAS is $2.5-3 \%$ in the limited literature $(37,38)$. DAS affects more frequently the bronchus intermedius, causing what is known as vanishing bronchus intermedius syndrome (VBIS) (4). VBIS is associated with high mortality and mean survival of 25 months after the initial diagnosis (38).

Several treatment options are often employed include balloon bronchoplasty, endobronchial stent placement, laser therapy, electrocautery, argon plasma coagulation, and cryotherapy. These procedures are usually performed in combination. The treatment choice for bronchial stenosis varies depending on the location and severity of the stenosis, and the institution's availability of interventional bronchoscopy procedures and expertise.

Balloon dilation is often the initial interventional procedure for bronchial stenosis. Usually, multiple balloon dilation procedures are required overtime due to recurrent airway stenosis and based on the severity of the patient's symptoms (39). Bronchial balloon dilation is frequently performed in combination with endobronchial stent placement $(4,7,39,40)$.

Self-expanding metallic stents and silicone stents are usually reserved for cases of severe and refractory stenosis due to the high incidence of complications related to stents such as mucous impaction, granulation tissue formation, dislodgement, and migration (38-43). Case reports using both biodegradable stents, as well as lobar stents, exist, though more extensive prospective studies are needed to validate their safety and efficacy $(42,43)$.

Cryotherapy, endobronchial electrocautery knife, or Neodymium-yttrium-aluminum-garnet (Nd:YAG) laser have been used in the management of bronchial stenosis after lung transplant (44).

Few centers have reported successful results using highdose-rate (HDR) endobronchial brachytherapy as an option in patients who have refractory bronchial stenosis (45-47).

When attempts at balloon dilation and stenting fail, surgical strategies include retransplantation, lobectomy, wedge bronchoplasty of the bronchus intermedius, and isolated sleeve resection of the bronchus intermedius (48-51). This situation is rare, so reliable data on surgical outcomes are lacking.

\section{Debiscence}

Dehiscence is believed to be the result of severe airway necrosis, and it is usually within one to five weeks after transplantation (52). The incidence of anastomotic dehiscence ranges between 1-10\% (4,52). Dehiscence is associated with high mortality, and early diagnosis and intervention are essential. Chest computed tomography (CT) can detect defects in the bronchial wall, showing bronchial narrowing or extraluminal air (53). However, bronchoscopy remains the gold standard for the diagnosis and guides further management.

The management of bronchial necrosis and dehiscence depends on the severity of the necrosis and the presence of any associated complications. Conservative management with antibiotic treatment and surveillance bronchoscopy is indicated for necrosis, which affects only the bronchial mucosa but not the bronchial wall, and when no airleak is present (54). For clinically significant bronchial anastomotic dehiscence, some experts suggest placement of an uncovered self-expanding metallic stent, which appears to facilitate healing by stimulating neo-epithelialization 
(40,52). Surgical interventions like reanastomosis, flap bronchoplasty, or in rare cases, retransplantation, have been considered in patients who have severe dehiscence or have a failure to more conservative measurements. However, reconstructive surgical approaches for dehiscence have been risky and disappointing (55-57).

\section{Tracheobronchomalacia (TBM)}

A diagnostic criterion of greater than $50 \%$ reduction in the luminal caliber on expiration has been widely used for the diagnosis of malacia (58). In the lung transplant population, TBM can be classified as perianastomotic malacia, localized within $1 \mathrm{~cm}$ of the anastomosis site, and diffuse involving anastomosis and extending beyond $1 \mathrm{~cm}$ (5). Patients can present with symptoms similar to airway stenosis, with dyspnea, inability to clear secretions, recurrent infections, wheezing, and a 'barking' cough, which is unique to bronchomalacia. Declining flow rates on spirometry with abnormal flow-volume loop patterns showing a variable obstruction, more marked during expiration. Bronchoscopy is the gold standard for the diagnosis of TBM, demonstrating a dynamic visualization of the airway during expiration.

The management of TBM in transplant patients is similar to that of the nontransplant-related malacia. The decision to treat TBM depends on the severity of symptoms and the extent of airway collapse. If infection or rejection is present, specific treatment may provide symptomatic relief. Patients with moderate airway collapse may benefit from one or more of the following: airway clearance techniques (e.g., oscillatory device or percussion vest), maintenance of airway hydration with saline nebulizer treatments, mucolytics, and non-invasive ventilation (NIV) (59-61). If significant symptoms and functional impairment persist despite conservative medical management, endobronchial stent placement may improve symptoms by establishing and maintaining patency of the malacic airway segment $(62,63)$. Silicone stents are generally preferable, as they are more easily repositioned. Surgical interventions, including resection, reconstruction, tracheoplasty, and retransplantation, are additional options $(64,65)$. However, this situation is rare, so data on surgical outcomes in lung transplant recipients are lacking.

\section{Summary}

ACs after lung transplantation remain an important source of morbidity and mortality despite significant advances in the surgical technics, leading to increased cost and decrease quality of life. The true incidence of airway ischemic complications after lung transplantation remains unclear.

ACs might be prevented by early recognition of the airway pathology, using advance medical management, and interventional bronchoscopy procedures. The best therapeutic approach in the management of ACs after lung transplant is often limited due to the lack of adequate data and is usually individualized to center preference and based on the location of the airway pathology. The 2018 ISHLT universal lung transplant airway grading system will help to determine the true prevalence and outcome of airway pathology, allowing the creation of future management strategies.

\section{Acknowledgments}

Funding: None.

\section{Footnote}

Provenance and Peer Review: This article was commissioned by the Guest Editor (Jonathan D'Cunha) for the series "Lung Transplantation: Past, Present, and Future" published in Fournal of Thoracic Disease. The article has undergone external peer review.

Conflicts of Interest: The author has completed the ICMJE uniform disclosure form, available at: https:// dx.doi.org/10.21037/jtd-20-2696. The series "Lung Transplantation: Past, Present, and Future" was commissioned by the editorial office without any funding or sponsorship. The author has no other conflicts of interest to declare.

Ethical Statement: The author is accountable for all aspects of the work in ensuring that questions related to the accuracy or integrity of any part of the work are appropriately investigated and resolved.

Open Access Statement: This is an Open Access article distributed in accordance with the Creative Commons Attribution-NonCommercial-NoDerivs 4.0 International License (CC BY-NC-ND 4.0), which permits the noncommercial replication and distribution of the article with the strict proviso that no changes or edits are made and the original work is properly cited (including links to both the 
formal publication through the relevant DOI and the license). See: https://creativecommons.org/licenses/by-nc-nd/4.0/.

\section{References}

1. Wildevuur CR, Benfield JR. A review of 23 human lung transplantations by 20 surgeons. Ann Thorac Surg 1970;9:489-515.

2. Schmid RA, Boehler A, Speich R, et al. Bronchial anastomotic complications following lung transplantation: still a major cause of morbidity? Eur Respir J 1997;10:2872-5.

3. Murthy SC, Blackstone EH, Gildea TR, et al. Impact of anastomotic airway complications after lung transplantation. Ann Thorac Surg 2007;84:401-9.e4094.

4. Santacruz JF, Mehta AC. Airway complications and management after lung transplantation: ischemia, dehiscence, and stenosis. Proc Am Thorac Soc 2009;6:79-93.

5. Crespo MM, McCarthy DP, Hopkins PM, et al. ISHLT Consensus Statement on adult and pediatric airway complications after lung transplantation: Definitions, grading system, and therapeutics. J Heart Lung Transplant 2018;37:548-63.

6. Kshettry VR, Kroshus TJ, Hertz MI, et al. Early and late airway complications after lung transplantation: incidence and management. Ann Thorac Surg 1997;63:1576-83.

7. Mulligan MS. Endoscopic management of airway complications after lung transplantation. Chest Surg Clin N Am 2001;11:907-15.

8. Wilson IC, Hasan A, Healey M, et al. Healing of the bronchus in pulmonary transplantation. Eur $\mathrm{J}$ Cardiothorac Surg 1996;10:521-6; discussion 526-7.

9. Ramirez J, Patterson GA. Airway complications after lung transplantation. Semin Thorac Cardiovasc Surg 1992;4:147-53.

10. Walker CM, Rosado-de-Christenson ML, MartínezJiménez S, et al. Bronchial arteries: anatomy, function, hypertrophy, and anomalies. Radiographics 2015;35:32-49.

11. Ruttmann E, Ulmer H, Marchese M, et al. Evaluation of factors damaging the bronchial wall in lung transplantation. J Heart Lung Transplant 2005;24:275-81.

12. Date H, Trulock EP, Arcidi JM, et al. Improved airway healing after lung transplantation. An analysis of 348 bronchial anastomoses. J Thorac Cardiovasc Surg 1995;110:1424-32; discussion 1432-3.

13. Yokomise H, Cardoso PF, Kato H, et al. The effect of pulmonary arterial flow and positive end-expiratory pressure on retrograde bronchial mucosal blood flow. J Thorac Cardiovasc Surg 1991;101:201-8.

14. Garfein ES, McGregor CC, Galantowicz ME, et al. Deleterious effects of telescoped bronchial anastomosis in single and bilateral lung transplantation. Ann Transplant 2000;5:5-11.

15. Garfein ES, Ginsberg ME, Gorenstein L, et al. Superiority of end-to-end versus telescoped bronchial anastomosis in single lung transplantation for pulmonary emphysema. J Thorac Cardiovasc Surg 2001;121:149-54.

16. Khaghani A, Tadjkarimi S, al-Kattan K, et al. Wrapping the anastomosis with omentum or an internal mammary artery pedicle does not improve bronchial healing after single lung transplantation: results of a randomized clinical trial. J Heart Lung Transplant 1994;13:767-73.

17. Van De Wauwer C, Van Raemdonck D, Verleden GM, et al. Risk factors for airway complications within the first year after lung transplantation. Eur J Cardiothorac Surg 2007;31:703-10.

18. Pettersson GB, Yun JJ, Nørgaard MA. Bronchial artery revascularization in lung transplantation: techniques, experience, and outcomes. Curr Opin Organ Transplant 2010;15:572-7.

19. Tong MZ, Johnston DR, Pettersson GB. The role of bronchial artery revascularization in lung transplantation. Thorac Surg Clin 2015;25:77-85.

20. Guzman-Pruneda FA, Orr Y, Trost JG, et al. Bronchial artery revascularization and en bloc lung transplant in children. J Heart Lung Transplant 2016;35:122-9.

21. FitzSullivan E, Gries CJ, Phelan P, et al. Reduction in airway complications after lung transplantation with novel anastomotic technique. Ann Thorac Surg 2011;92:309-15.

22. Weder W, Inci I, Korom S, et al. Airway complications after lung transplantation: risk factors, prevention and outcome. Eur J Cardiothorac Surg 2009;35:293-8; discussion 298.

23. Mason DP, Brown CR, Murthy SC, et al. Growing singlecenter experience with lung transplantation using donation after cardiac death. Ann Thorac Surg 2012;94:406-11; discussion 411-2.

24. De Oliveira NC, Osaki S, Maloney JD, et al. Lung transplantation with donation after cardiac death donors: long-term follow-up in a single center. J Thorac Cardiovasc Surg 2010;139:1306-15.

25. Colquhoun IW, Gascoigne AD, Au J, et al. Airway complications after pulmonary transplantation. Ann Thorac Surg 1994;57:141-5.

26. Cypel M, Yeung JC, Liu M, et al. Normothermic ex vivo 
lung perfusion in clinical lung transplantation. N Engl J Med 2011;364:1431-40.

27. Gammie JS, Stukus DR, Pham SM, et al. Effect of ischemic time on survival in clinical lung transplantation. Ann Thorac Surg 1999;68:2015-9; discussion 2019-20.

28. Snell GI, Rabinov M, Griffiths A, et al. Pulmonary allograft ischemic time: an important predictor of survival after lung transplantation. J Heart Lung Transplant 1996;15:160-8.

29. Grimm JC, Valero V 3rd, Kilic A, et al. Association Between Prolonged Graft Ischemia and Primary Graft Failure or Survival Following Lung Transplantation. JAMA Surg 2015;150:547-53.

30. Keshavjee SH, Yamazaki F, Yokomise H, et al. The role of dextran 40 and potassium in extended hypothermic lung preservation for transplantation. J Thorac Cardiovasc Surg 1992;103:314-25.

31. Okada Y, Kondo T. Preservation solution for lung transplantation. Gen Thorac Cardiovasc Surg 2009;57:635-9.

32. Chen CZ, Gallagher RC, Ardery P, et al. Retrograde flush and cold storage for twenty-two to twenty-five hours lung preservation with and without prostaglandin E1. J Heart Lung Transplant 1997;16:658-66.

33. Herrera JM, McNeil KD, Higgins RS, et al. Airway complications after lung transplantation: treatment and long-term outcome. Ann Thorac Surg 2001;71:989-93; discussion 993-4.

34. Nunley DR, Gal AA, Vega JD, et al. Saprophytic fungal infections and complications involving the bronchial anastomosis following human lung transplantation. Chest 2002;122:1185-91.

35. McAnally KJ, Valentine VG, LaPlace SG, et al. Effect of pre-transplantation prednisone on survival after lung transplantation. J Heart Lung Transplant 2006;25:67-74.

36. Groetzner J, Kur F, Spelsberg F, et al. Airway anastomosis complications in de novo lung transplantation with sirolimus-based immunosuppression. J Heart Lung Transplant 2004;23:632-8.

37. Hasegawa T, Iacono AT, Orons PD, et al. Segmental nonanastomotic bronchial stenosis after lung transplantation. Ann Thorac Surg 2000;69:1020-4.

38. Souilamas R, Wermert D, Guillemain R, et al. Uncommon combined treatment of nonanastomotic bronchial stenosis after lung transplantation. J Bronchology Interv Pulmonol 2008; $15: 54-5$.

39. Chhajed PN, Malouf MA, Tamm M, et al. Interventional bronchoscopy for the management of airway complications following lung transplantation. Chest 2001;120:1894-9.

40. Kapoor BS, May B, Panu N, et al. Endobronchial stent placement for the management of airway complications after lung transplantation. J Vasc Interv Radiol 2007;18:629-32.

41. Sundset A, Lund MB, Hansen G, et al. Airway complications after lung transplantation: long-term outcome of silicone stenting. Respiration 2012;83:245-52.

42. Fernandez-Bussy S, Labarca G, Majid A. Biodegradable stent for vanishing bronchus syndrome after lung transplantation. J Heart Lung Transplant 2016;35:1378-9.

43. Sethi S, Gildea TR, Almeida FA, et al. Clinical Success Stenting Distal Bronchi for "Lobar Salvage" in Bronchial Stenosis. J Bronchology Interv Pulmonol 2018;25:9-16.

44. Fitzmaurice GJ, Redmond KC, Fitzpatrick DA, et al. Endobronchial cryotherapy facilitates end-stage treatment options in patients with bronchial stenosis: A case series. Ann Thorac Med 2014;9:120-3.

45. Halkos ME, Godette KD, Lawrence EC, et al. High dose rate brachytherapy in the management of lung transplant airway stenosis. Ann Thorac Surg 2003;76:381-4.

46. Kennedy AS, Sonett JR, Orens JB, et al. High dose rate brachytherapy to prevent recurrent benign hyperplasia in lung transplant bronchi: theoretical and clinical considerations. J Heart Lung Transplant 2000;19:155-9.

47. Meyer A, Warszawski-Baumann A, Baumann R, et al. HDR brachytherapy: an option for preventing nonmalignant obstruction in patients after lung transplantation. Strahlenther Onkol 2012;188:1085-90.

48. Marulli G, Loy M, Rizzardi G, et al. Surgical treatment of posttransplant bronchial stenoses: case reports. Transplant Proc 2007;39:1973-5.

49. Camargo Jde J, Camargo SM, Machuca TN, et al. Surgical maneuvers for the management of bronchial complications in lung transplantation. Eur J Cardiothorac Surg 2008;34:1206-9.

50. Paulson EC, Singhal S, Kucharczuk JC, et al. Bronchial sleeve resection for posttransplant stricture. Ann Thorac Surg 2003;76:2075-6.

51. Schäfers HJ, Schäfer CM, Zink C, et al. Surgical treatment of airway complications after lung transplantation. J Thorac Cardiovasc Surg 1994;107:1476-80.

52. Mughal MM, Gildea TR, Murthy S, et al. Short-term deployment of self-expanding metallic stents facilitates healing of bronchial dehiscence. Am J Respir Crit Care Med 2005;172:768-71.

53. Semenkovich JW, Glazer HS, Anderson DC, et al. Bronchial dehiscence in lung transplantation: CT 
evaluation. Radiology 1995;194:205-8.

54. Clark NM, Weigt SS, Fishbein MC, et al. Fungal Infections Complicating Lung Transplantation. Semin Respir Crit Care Med 2018;39:227-54.

55. D'Andrilli A, Ibrahim M, Andreetti C, et al. Transdiaphragmatic harvesting of the omentum through thoracotomy for bronchial stump reinforcement. Ann Thorac Surg 2009;88:212-5.

56. Deeb ME, Sterman DH, Shrager JB, et al. Bronchial anastomotic stricutre caused by ossification of an intercostal muscle flap. Ann Thorac Surg 2001;71:1700-2.

57. McGiffin D, Wille K, Young K, et al. Salvaging the dehisced lung transplant bronchial anastomosis with homograft aorta. Interact Cardiovasc Thorac Surg 2011;13:666-8.

58. Murgu S, Colt H. Tracheobronchomalacia and excessive dynamic airway collapse. Clin Chest Med 2013;34:527-55.

59. Sirithangkul S, Ranganathan S, Robinson PJ, et al. Positive expiratory pressure to enhance cough effectiveness in tracheomalacia. J Med Assoc Thai 2010;93 Suppl 6:S112-8.
60. Ferguson GT, Benoist J. Nasal continuous positive airway pressure in the treatment of tracheobronchomalacia. Am Rev Respir Dis 1993;147:457-61.

61. Wiseman NE, Duncan PG, Cameron CB. Management of tracheobronchomalacia with continuous positive airway pressure. J Pediatr Surg 1985;20:489-93.

62. Ernst A, Majid A, Feller-Kopman D, et al. Airway stabilization with silicone stents for treating adult tracheobronchomalacia: a prospective observational study. Chest 2007;132:609-16.

63. Murgu SD, Colt HG. Complications of silicone stent insertion in patients with expiratory central airway collapse. Ann Thorac Surg 2007;84:1870-7.

64. Majid A, Guerrero J, Gangadharan S, et al. Tracheobronchoplasty for severe tracheobronchomalacia: a prospective outcome analysis. Chest 2008;134:801-7.

65. Wright CD, Grillo HC, Hammoud ZT, et al. Tracheoplasty for expiratory collapse of central airways. Ann Thorac Surg 2005;80:259-66.
Cite this article as: Crespo MM. Airway complications in lung transplantation. J Thorac Dis 2021;13(11):6717-6724. doi: $10.21037 /$ jtd-20-2696 